\title{
Mechanisms Responsible for Cognitive Impairment in Epilepsy
}

\author{
Pierre-Pascal Lenck-Santini ${ }^{1}$ and Rodney C. Scott ${ }^{2}$ \\ ${ }^{1}$ Department of Neurological Sciences, University of Vermont, Burlington, Vermont 05405 \\ ${ }^{2}$ Institute of Child Health, University College of London, London WC1N 3JH, United Kingdom \\ Correspondence: pierre-pascal.lenck-santini@med.uvm.edu
}

Epilepsy is often associated with cognitive and behavioral impairments that can have profound impact on the quality of life of patients. Although the mechanisms of cognitive impairment are not completely understood, we make an attempt to describe, from a systems perspective, how information processing is affected in epilepsy disorders. The aim of this review is to (1) define the nature of cognitive deficits associated with epilepsy, (2) review fundamental systems-level mechanisms underlying information processing, and (3) describe how information processing is dysfunctional in epilepsy and investigate the relative contributions of etiology, seizures, and interictal discharges (IDs). We conclude that these mechanisms are likely to be important and deserve more detailed scrutiny in the future.

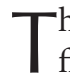
he epilepsies are a group of disorders defined by the propensity for an individual to have epileptic seizures (Fisher et al. 2014). In addition to seizures, these common and serious neurological disorders are associated with cognitive and behavioral impairments (Berg and Scheffer 2011). The cognitive and behavioral impairments are critical determinants of the reductions in quality of life observed in patients with epilepsy (Ronen et al. 2003; Loring et al. 2004). It is, therefore, of major importance that the mechanisms underlying cognitive impairments are characterized as this is likely to lead to novel interventions that will ultimately improve the quality of life of people with epilepsy. Epilepsy is associated with a variety of physiological and molecular alterations at the level of changes in the genome, gene expression, receptor characteristics, peptides, and brain injury. These changes are not only responsible for seizures but also for functional abnormalities underlying cognitive impairment. It is likely that several of these mechanisms are occurring in concert, and, therefore, it is important to study the net effects of these alterations at the level of neural networks as this may also lead to novel interventions that could improve outcomes. The aims of this article are to (1) define the nature of cognitive deficits associated with epilepsy, (2) review fundamental systems-level mechanisms underlying information processing, and (3) describe how information processing is dysfunctional in epilepsy and investigate the relative contributions of etiology, seizures, and interictal discharges (IDs).

Editors: Gregory L. Holmes and Jeffrey L. Noebels

Additional Perspectives on Epilepsy: The Biology of a Spectrum Disorder available at www.perspectivesinmedicine.org

Copyright (C) 2015 Cold Spring Harbor Laboratory Press; all rights reserved; doi: 10.1101/cshperspect.a022772

Cite this article as Cold Spring Harb Perspect Med 2015;5:a022772 
P.-P. Lenck-Santini and R.C. Scott

\section{THE NATURE OF COGNITIVE IMPAIRMENTS IN PEOPLE WITH EPILEPSY}

Cognitive impairments in epilepsy are a consequence of complex interactions among the etiologies of the epilepsy, the seizures themselves, interictal discharges, and antiepileptic drugs (Raspall-Chaure et al. 2008). Cognitive impairments are often most severe in people with epilepsy that began in childhood, particularly in those epilepsies that are classified as epileptic encephalopathies. The cognitive deficits in children with epilepsy are manifest as a reduction in average IQ that leads to many children requiring special education interventions. An impact on at least one academic area is identified in 50\% of children with epilepsy (Vinayan et al. 2005; Fastenau et al. 2008). It is important to note that even those children functioning at or near an average IQ often underachieve with respect to performance expected for that IQ (Oostrom et al. 2003). In the school setting, $\sim 45 \%$ of children with epilepsy and an IQ of at least 80 require special education services, and $16 \%$ of these children repeat a year of education (Aldenkamp et al. 1990; Berg et al. 2011). There are also more specific abnormalities identified in both reading skills (including single-word, phonological awareness, comprehension, and speed or fluency deficits) and math skills (Croona et al. 1999; Chaix et al. 2006; Pinton et al. 2006; Canavese et al. 2007; Clarke et al. 2007; Felker et al. 2011; Verrotti et al. 2011). Often, several educational areas are affected in individuals. In addition, children with epilepsy frequently show more general deficits in the domains of memory and attention (Croona et al. 1999; Sanchez-Carpintero and Neville 2003; Northcott et al. 2005; Chaix et al. 2006; Deltour et al. 2007). Although many children maintain IQ over time, there are some children that lose skills, particularly with changes in seizure frequency or seizure severity.

Studies trying to identify predictors of cognitive impairments have largely concentrated on seizure-related factors. These factors include early onset of seizures (Bulteau et al. 2000; Bjornaes et al. 2001), high seizure frequency (Hermann et al. 2002), seizure intractability (Farwell et al. 1985; Seidenberg et al. 1986), and length of time that an individual has had seizures. In addition, there are some seizure syndromes that are far more likely to be associated with cognitive impairment (e.g., infantile spasms, Dravet syndrome, and Lennox-Gastaut syndrome). Affected children usually have severe cognitive impairments, but it is clear that there may be more subtle cognitive deficits in children with other types of epilepsy, such as benign rolandic epilepsy or childhood absence epilepsy (Vinayan et al. 2005; Caplan et al. 2008). It is critical to recognize that the correlations among seizure parameters (length, frequency, duration, etc.) are never very tight within epilepsy syndrome and when compared across syndromes, such correlations are usually not identified. For example, the number and anatomical site of interictal spikes during sleep in children with Landau-Kleffner syndrome and benign rolandic epilepsy are similar but the outcomes are vastly different suggesting that other factors, such as etiology, must be contributing to outcomes.

Adults with epilepsy also display cognitive impairments, which are largely related to the area of the brain that is the focus of the epilepsy. For example, adults with temporal lobe epilepsy display memory impairments (Bell et al. 2011). However, adults with generalized epilepsies like juvenile myoclonic epilepsy may display mild cognitive impairments (Hubel and Wiesel 1959).

The association between cognitive impairment and seizure characteristics is often viewed as causative (i.e., the change in seizure characteristics cause the change in cognitive ability). However, brain function is dynamic, and changes in brain function that lead to seizures could independently be causing a change in cognition (a complex interaction among etiology, seizures, and cognition). This observation could help to explain the limited impact of antiepileptic drugs and epilepsy surgery on cognitive outcomes. It strongly supports the view that seizure-centric constructs for understanding the relationships between cognition and epilepsy need to be expanded to include the impacts of etiology. Further, it shows that neural systems that underlie cognitive processing are likely dis- 
rupted in patients with epilepsy. The goal of the following sections is to review systems-level mechanisms of information processing and to show how these mechanisms are disrupted in a variety of animal models with relevance to human epilepsy and where available in humans.

\section{Systems-Level Mechanisms Underpinning Information Processing and Memory}

Information processing for the purposes of this article refers to acquisition, storage, and retrieval of information. In the nervous system, sensory inputs into neural networks are processed in a way that that these networks collectively guide behavior, encode and retrieve memories, and create consciousness through emergent and complex properties of the network. Neural networks can be investigated at a variety of scales including at the level of the synapse, the level of single-neuron firing characteristics, and at the level of the ensembles of neurons producing oscillatory activity in the brain. Several mechanisms for the relationship between neuronal firing and information encoding have been proposed: frequency coding, population coding, and temporal coding. In addition, these processes are likely modulated by synaptic plasticity and by oscillatory activity. Although these mechanisms will be described separately, many of these processes are occurring simultaneously within the same network and should not be conceptualized as independent mechanisms. In describing these coding mechanisms, we will focus on two major structures commonly affected by seizures: the neocortex and the hippocampus. Before exploring the effect of epilepsies on these processes, it is important to understand their physiological roles.

\section{Rate Coding}

In rate coding, it is the number of action potentials fired by a neuron that carries information. This information can be the orientation of a moving visual stimulus in the visual cortex (Hubel and Wiesel 1959), the direction of movement of the hand in the motor cortex (Georgopoulos et al. 1982), but also more ab- stract notions, such as the presentation of a celebrity picture (Fried et al. 1997; Quian et al. 2014), personally relevant images (Viskontas et al. 2009), or one's location in the environment. In the hippocampal formation, rate coding is illustrated by place cells (O'Keefe and Nadel 1978) and in the entorhinal cortex by grid cells (Moser et al. 2008). Place cells (Fig. 1A) are hippocampal pyramidal cells recorded in rodents that are only active when the animal enters a specific region of the environment, called the cell's place field. At a given time, it is estimated that $30 \%-40 \%$ of hippocampal pyramidal cells act as place cells with place fields covering the totality of the environment (Muller 1996). Each time the rat is reintroduced to the same environment, the same set of cells is activated and their place fields are identical, suggesting that place-cell representation is remembered and not built de novo (Muller 1996). Together with the fact that hippocampal lesions abolish spatial memory in rodents, the place-cell phenomenon leads to the hypothesis that the place-cell firing is the neural substrate of spatial representations. In the entorhinal cortex, grid cells are pyramidal neurons that have multiple place fields of the same size organized in a periodic triangular array and cover the whole environment. Such organization has been proposed to be involved in path integration, a process by which motion cues are integrated to orient and navigate in the environment.

\section{Population Coding}

In population coding, information is carried out by the joint activation of an ensemble of neurons rather than individual neurons within this ensemble. This method is particularly insensitive to variations in the activity of individual neurons caused by noise, thereby decreasing the uncertainty of the signal and processing time. An example of population coding is the activity of primary motor cortex neurons in macaques trained to reach targets organized in a circle. Although individual neurons preferentially increase their firing for a specific direction of movement, the activity of the ensemble of 
P.-P. Lenck-Santini and R.C. Scott

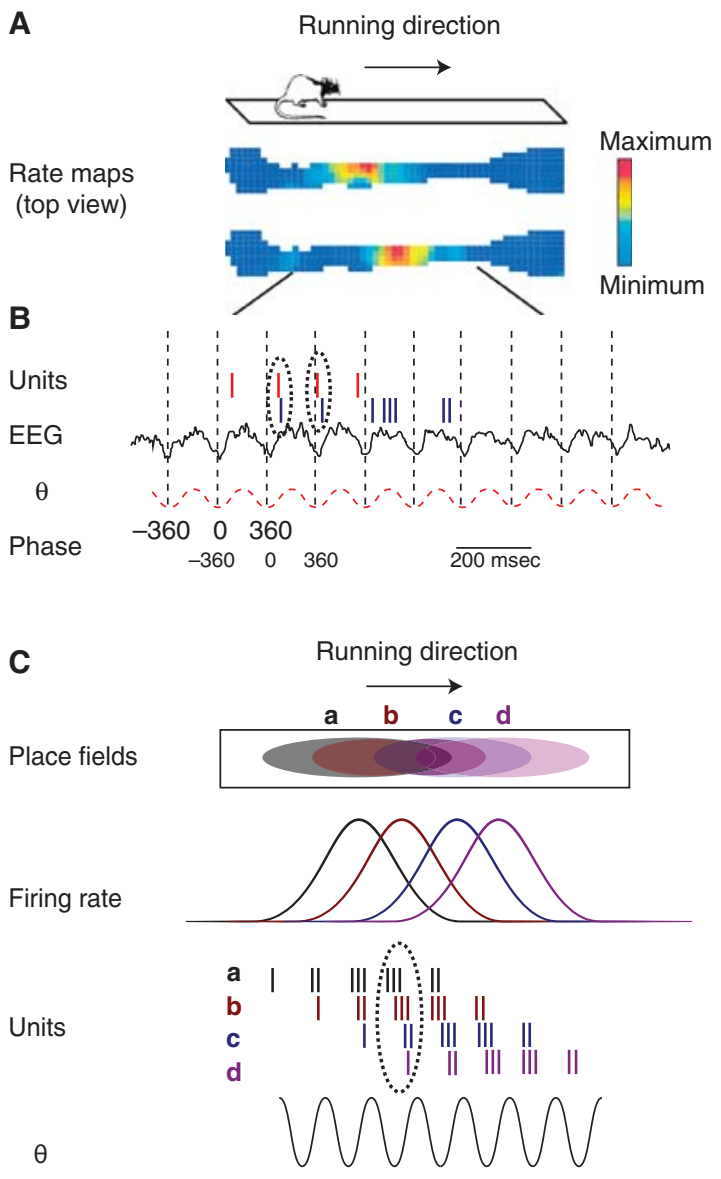

Figure 1. Hippocampal place cells and their relationship with $\theta$ rhythm. (A) Two place cells recorded simultaneously as the rat crosses a linear track. The firing activity of each cell is represented by a rate map of the environment viewed from the top. Blue color, no activity; red, maximum firing of each cell $(\sim 30 \mathrm{~Hz})$. This is a typical example of rate coding. (B) Phase precession. Activity of each cell (vertical bar, one action potential) for the top (red bars) and bottom (blue bars) cells in A. Firing activity is overlaid with the ongoing hippocampal electroencephalograph (EEG) (black trace) during a single crossing of the track. The EEG has also been filtered in the $\theta$ band (red dashed trace, $4-12 \mathrm{~Hz}$ ). Note that each cell fires at an earlier phase than in the previous cycle. This phenomenon, called phase precession, is an example of temporal coding. The two cells, having a partially overlapping field, start the precession process at a different cycle. This results in a systematic firing lag between the two cells within a single $\theta$ cycle (dotted ellipses). The time lag is proportional to the overlap among the place fields. $(C)$ At the population level, when multiple partially overlapping fields are being crossed, phase precession leads to the reactivation in each $\theta$ cycle $(\sim 120 \mathrm{msec})$ of the sequence of place cells being currently activated. Each place field is represented in the track viewed from the top (upper graph) or expressed in firing rate as a function of distance (second graph from top).

neurons (Georgopoulos et al. 1982) uniquely predicted the direction of motion. Subsequent studies (Salinas and Abbott 1994) have also shown that population coding accurately predicts stimulus features and behaviors in multiple brain areas and species, including localiza- tion of a rat on the basis of place-cell activity (Wilson and McNaughton 1993) or insect escape behavior from a giant interneuron population (Levi and Camhi 2000). Another way of conceptualizing population coding is as a network of neurons firing in a coordinated fashion 
and in which there are parameters that predict behavior in a maze (Tyler et al. 2012).

\section{Temporal Coding}

Temporal coding is the process by which the precise timing of action potential firing, in the order of milliseconds, carries information. Here, the timing can be relative to stimulus presentation, response onset, the firing of individual neurons/population of neurons, or an ongoing oscillation in the electroencephalograph (EEG). A major argument in favor of the temporal coding hypothesis is the notion of coincidence detection. Because a single synaptic input is not sufficient by itself to induce firing in a neuron (excitatory postsynaptic potentials [EPSPs] generally account for a maximum of $1 \mathrm{mV}$ ), synaptic inputs need either to involve large numbers of neurons firing at a high rate or to be precisely timed (synchronized within $5 \mathrm{msec}$ ) so that EPSPs, produced at various locations in the dendritic tree, can efficiently induce postsynaptic firing. Examples of millisecond neuronal synchrony have been observed in several species and brain areas, including the auditory cortex in owls (Wagner et al. 2005) and the visual cortex in monkeys (Gray et al. 1989). Changes in synchrony among neurons can be observed independently of the firing rates of these individual neurons (Kilavik et al. 2014), suggesting that it is an independent process from rate coding. It is proposed that neurons that fire synchronously participate in the same process and form, as an ensemble, a coding entity. Finally, as we have seen above, millisecond-range synchrony among neurons plays a critical role for synaptic plasticity and storage of information.

\section{Synaptic Plasticity}

The types of coding described above are, at least in part, a function of synaptic plasticity. Synaptic plasticity is the process by which the ability of a synapse to transmit information among neurons (in the form of EPSPs or inhibitory postsynaptic potentials [IPSPs]) is modified in response to changes in neuronal inputs. There are two common forms of plasticity studied in laboratory settings: long-term and shortterm plasticity. The first evidence of long-term synaptic plasticity was provided by Bliss and Lomo (1973). They found that tetanic stimulation $(100 \mathrm{~Hz})$ of the perforant path induced a long-lasting augmentation of the postsynaptic response to single perforant path stimulation in the dentate gyrus. This phenomenon, called long-term potentiation (LTP), involves $N$-methyl-D-aspartate (NMDA) and $\alpha$-amino3-hydroxl-5-methyl-4-isoxazole-propionate (AMPA) receptors as well as various protein kinases and, in the long term, changes in gene expression. Alterations of LTP, as well as the opposite phenomenon (long-term depression [LTD]), have been shown to affect learning and memory. For instance, blockade of NMDA receptors prevents the induction of LTP in vivo and causes a selective impairment of spatial learning in spatial memory tasks (Morris et al. 1986), and reduction of protein kinase $M$ $(\mathrm{PKM})-\xi$, a protein kinase $\mathrm{C}$ isoform critical for LTP maintenance, abolishes already acquired memories (Pastalkova et al. 2006). Placecell stability also requires maintenance of LTP (McHugh et al. 1996; Cho et al. 1998; Kentros et al. 1998; Dragoi et al. 2003; Agnihotri et al. 2004; Barry et al. 2012) further supporting the view that synaptic plasticity is an important mechanism underlying spatial cognition. Shortterm plasticity, occurring in the time scale of milliseconds to minutes, relies on different mechanisms (depletion of synaptic vesicles, calcium signaling) and is believed to play a critical role in information processing (filtering, gain control) and working memory.

\section{Oscillatory Activity}

Brain oscillations are periodic fluctuations of the activity of groups of neurons. They mainly result from the synchronous activation of synaptic currents (IPSPs and inhibitory postsynaptic currents [IPSCs]) of large populations of neurons (Buzsaki et al. 2012). In the past two decades, evidence has been accumulating in favor of a critical role of brain oscillations in various aspects of the coding mechanisms 
described above, given that neuronal synchrony organizes temporal coding and, thus, plays a critical role in synaptic plasticity. Oscillations are observed in scalp EEG, electrocorticograms, and local field potentials recorded from intracranial electrodes. They range from 0.05 to $600 \mathrm{~Hz}$, usually in combination with each other. This signal can be decomposed into individual frequency bands that historically were named after Greek letters: $\delta(0.5-4 \mathrm{~Hz}), \theta(4-8 \mathrm{~Hz}$ in human scalp EEG; $4-12 \mathrm{~Hz}$ in rodent hippocampus $), \alpha(8-12 \mathrm{~Hz}), \beta(15-30 \mathrm{~Hz})$, and $\gamma$ $(30-90 \mathrm{~Hz})$. Other oscillation types, including ultraslow oscillations (for a review, see Buzsaki et al. 2012) and high-frequency oscillations or ripples $(100-300 \mathrm{~Hz})$ have also been observed. There is now overwhelming evidence that $\gamma$ aminobutyric acid (GABA)ergic interneurons play a critical role in organizing network dynamics that are a fundamental part of information processing. For example, perisomatic-targeting interneurons (most of them expressing parvalbumin $[\mathrm{PV}]$ ), directly control the output of the pyramidal cells to which they are connected. By innervating a large number of pyramidal cells and interneurons, PV cells, such as basket cells, control the synchrony of large populations of neurons, resulting in major oscillatory patterns, such as $\gamma$ and $\theta$ (Bartos et al. 2007; Klausberger and Somogyi 2008). Dendritic projecting interneurons, on the other hand, control the input flow of information within the hippocampus. Oriens lacunosum moleculare (OLM) cells, for example, inhibit entorhinal entries to CA1 while facilitating CA3 inputs. Finally, $\theta$ and other hippocampal oscillatory patterns, such as sharpwave ripples, are also controlled by GABAergic interneurons in the medial septum/diagonal band (MS/DB) of Broca (Hangya et al. 2009).

We will focus on the major oscillations that influence the hippocampus and connected structures: $\theta$ and $\gamma$ rhythms. $\theta$ Rhythm is a high-voltage $(2 \mathrm{mV})$ regular sinusoidal oscillation $(5-12 \mathrm{~Hz})$ observed during exploration and rapid eye movement (REM) sleep in rodents as well as during virtual navigation, working memory, and REM sleep in humans (Cantero et al. 2003). In rodents, suppression of $\theta$ by medial septum (a major $\theta$ pacemaker) injection of muscimol (a $\mathrm{GABA}_{\mathrm{A}}$ agonist) induces profound spatial memory deficits similar to hippocampal resection (Winson 1978) and working memory deficits (Givens and Olton 1994). There are important relationships between the timing of single-neuron firing activity and the phase of $\theta$ oscillations, and this effect differs across cell types. Pyramidal cells preferentially fire at the trough of $\theta$, and basket cells shortly after the peak (Klausberger and Somogyi 2008). Place-cell activity and, to some extent, fast spiking interneurons (Geisler et al. 2010) have a more subtle relationship to $\theta$. As the rat crosses their place field, place-cell discharge oscillates at a faster rate than the ongoing $\theta$, with the action potentials appearing at earlier phases on successive $\theta$ cycles. By this phenomenon (Fig. 1B), called phase precession, the rat position is precisely encoded through the firing phase. Another consequence of phase precession is the fact that in each $\theta$ cycle (i.e., in an $\sim 120 \mathrm{msec}$ window) the activity of overlapping place cells is organized in sequences or chunks that reproduce the ongoing trajectory of the rat (Fig. 1C) (Dragoi et al. 2003; Gupta et al. 2012).

Of smaller amplitude but higher frequency than $\theta, \gamma$ rhythm also plays a role in information processing in both rodents (Bragin et al. 1995; Montgomery and Buzsaki 2007) and humans (Llinas and Ribary 1993; Canolty et al. 2006). It is believed that $\gamma$ rhythms provide coordinating mechanism-binding ensembles of neurons that encode information (Harris et al. 2003; Lisman 2005; Fries 2009). In the hippocampus, the magnitude of $\gamma$ oscillations is modulated by $\theta$ in that $\gamma$ is larger when $\theta$ waves go from peak to trough (Bragin et al. 1995). Inputs from the entorhinal cortex and from CA3 are coordinated at different $\gamma$ frequencies (Colgin et al. 2009), each riding at a different phase of $\theta$. It is proposed that such coordination of $\theta-\gamma$ oscillations plays a role in specific aspects of memory processing.

Oscillations not only play a role in information processing in a given structure but also in the communication among structures. Such communication is made possible by neuronal coherence, a mechanism by which oscillations in different brain areas become synchronized 
(Fries 2005). The idea is that neuronal groups participating in the same function oscillate together, which allows them to interact efficiently because their communication windows are open at the same times. Evidence for such a communication scheme has been observed in multiple frequency bands, brain regions, cognitive processes, and species (Lachaux et al. 1999; Miltner et al. 1999; Jones and Wilson 2005), and alterations of neuronal coherence are proposed to play a role in disorders, such as schizophrenia or attention-deficit hyperactivity disorder (ADHD) (Spencer et al. 2003; Uhlhaas and Singer 2010; Barry and Clarke 2013).

\section{DISRUPTION OF INFORMATION PROCESSING IN EPILEPSY}

In the previous sections, we have described some of the fundamental processing entities of the nervous system. In the following sections, we will describe the impacts of IDs, recurrent seizures, and etiology of seizures on information processing both in terms of behavior and in terms of the mechanisms previously described.

\section{The Impact of Epileptiform IDs}

A hallmark of epilepsy, IDs are high-amplitude paroxysmal potentials observed in periods between seizures. Although most attention is focused on seizures, there is concern as to whether interictal spikes could also alter cognitive function. Theoretically, harm could come in two ways: (1) IDs could alter ongoing cognitive processes (this will be referred to as "transient cognitive impairment" [TCI]), and (2) IDs could lead to long-term structural changes. Therefore, if IDs do alter neural substrates in the form of molecular changes, cell death, or sprouting of axonal projections, it is also possible that, in the long term, these changes alter the network functions involved in cognitive processing.

The question of whether IDs affect cognitive function directly was raised when the first EEG recordings in patients with epilepsy revealed spike and wave activity without apparent clinical manifestation (Gibbs et al. 1936) and when
Schwab (1939) showed that such "subclinical" activity was associated with a decreased reaction time. Since then, numerous studies have investigated the impact of IDs on cognition. These studies have led to conflicting results, feeding the ongoing controversy on whether treatments that minimize the frequency of IDs could improve cognitive outcomes (for a review, see Binnie 1994). Relevant to day-to-day life, IDs have been shown to impact reading and arithmetic skills in children, driving skills, and ability of air traffic controllers to effectively carry out their jobs (Binnie et al. 1987; Kasteleijn-Nolst Trenite et al. 1988; Kasteleijn-Nolst Trenite and Vermeiren 2005). The latter finding has driven the European agency for air safety (Eurocontrol) to use EEG monitoring as a screening tool. Therefore, there is compelling evidence that IDs have an effect on ongoing cognitive processes. This effect is location specific in the sense that the function that is altered is the one supported by the structure where IDs occur. Thus, cortical neural systems of information processing are disrupted at the time of the ID, although the precise effects of neuronal firing characteristics and oscillatory activity have not been characterized. Hippocampal IDs also affect cognitive processes. Using intracranial recordings in both temporal lobe epilepsy patients and animal models of the syndrome, Kleen et al. (2010, 2013) showed that IDs significantly affect the recall of information in working memory as long as the ID was at the precise time that information needed to be recalled from memory. IDs at other times during the task had no effect on memory (Kleen et al. 2013). Several clinicians consider this finding as a proof of principle that, at least in syndromes with a high-ID frequency, as in epileptic encepholopathies, the constant, repeated transient impairment caused by ID may have an additive and pervasive effect on general cognitive function (Holmes and Lenck-Santini 2006).

Overall, the magnitude of the behavioral impacts of IDs do not seem to be catastrophic, and it can be argued that the effect of IDs is mild compared with other factors, such as the etiology at the origin of seizures (Aldenkamp and Arends 2004a; Lucas et al. 2011). In a series of 
experiments, Aldenkamp and colleagues (Aldenkamp et al. 2001, 2004; Aldenkamp and Arends 2004b) carefully assessed the effect of ID recorded during cognitive testing while weighing this effect in comparison with other factors, such as seizure frequency and the effect of the clinical syndrome. The investigators conclude that IDs only have a mild effect on cognitive function, which is limited to transient processes (like attention or alertness) and is negligible when compared with other epilepsyrelated factors (Aldenkamp and Arends 2004a).

There is also a debate about whether frequent IDs impact cognition in a nontransitory way. Children with Landau-Kleffner syndrome and continuous spike-wave in slow wave sleep (CSWS) have frequent epileptic discharges during sleep and have significant cognitive (especially language) impairments (Van 2013). However, children with benign rolandic epilepsy also have frequent discharges in sleep but their cognitive outcomes are close to normal (Guerrini and Pellacani 2012). Therefore, magnitude of the negative impact of discharges could be small. The mechanism suggested for these impairments is that the discharges are disrupting physiological neural processes (e.g., memory consolidation). To address this, an animal model of frequent IDs using direct injections of bicucculine into the developing prefrontal cortex was developed (Hernan et al. 2014a,b). These animals have abnormalities in attention and in sociability, both functions related to the prefrontal cortex. In conjunction with the behavioral impacts, there are also abnormalities in a particular form of short-term potentiation (STP) with enhancement of the effect (Hernan et al. 2014a). It is likely that these plasticity changes represent a systems-level mechanism for the behavioral effects identified. Although a greater than normal effect leading to impairment may be counterintuitive, it is likely that the correct amount of STP is required for optimal brain function and that both increases and decreases in STP will be harmful. Interestingly, the IDs and STP changes were bilateral despite unilateral injections, suggesting that the ID itself has some negative impact on cortical neural systems.

\section{The Impact of Seizures}

In this section, we will concentrate on epileptic seizures induced in the context of a previously normal brain. Models of spontaneous seizures in the context of brain disease will be considered in the section on etiology.

Several aspects of neural systems including LTP, rate coding, and oscillatory activity have been studied. Alterations of LTP have been found after kindling (Reid and Stewart 1997; Schubert et al. 2005) and after pharmacologically induced seizures. Adult animals with previously normal brains exposed to 10 flurothyl-induced seizures have markedly reduced hippocampal LTP and behavioral impairment in the Morris water maze (Zhou et al. 2007), suggesting that seizures can disrupt plasticity mechanisms. Reduced LTP has been seen in humans with an epileptic focus in the hippocampus when compared with patients with a focus outside of the hippocampus (Beck et al. 2000).

Rate coding can be interrogated by investigating the effect of seizures on place-cell activity. Single daily flurothyl-induced seizures administered over 8 days in adult rats leads to reduction of the proportion of recorded pyramidal cells that meet the criteria for place cells (Lin et al. 2012). However, those cells that still meet the criteria have similar properties to those of cells recorded in control rodents. This is interpreted as a degradation of the place-cell system by recurrent seizures. In the same model, there is evidence for disruption of population coding. Peak frequencies in the $\theta$ range reduce over the 8 -day period, and if recording continues to day 19, this abnormality recovers. Therefore, induced seizures appear to have negative effects in the developed brain.

Children with severe epilepsies frequently have cognitive and behavioral impairments, and it is hypothesized that the seizures are permanently disrupting the development of the neural systems underpinning cognition. This hypothesis has also been tested in rodents. Recurrent flurothyl seizures induced during the neonatal period lead to an increase in LTP in the somatosensory cortex and to increases in STP in the prefrontal cortex (Isaeva et al. 
2010; Hernan et al. 2013). Similar effects on plasticity have also been identified following postnatal hypoxic seizures (Jensen 1999; Zhou et al. 2011). This suggests that seizures during development have permanent consequences to plasticity. Administration of 50-75 flurothyl seizures during early development leads to a permanent disruption of place-cell parameters in line with reductions in performance during Morris water-maze testing as adults (Karnam et al. 2009). There are reductions in the fidelity of firing (i.e., the firing is not extremely tightly related to position in space), the information content held in each action potential, firing rate inside the field, and increases in field size. Similar findings can also be identified following a single prolonged seizure induced with fever (Dubé et al. 2009). These findings are likely to be a systems-level mechanism explaining poor performance in a spatial task. However, the magnitudes of the effects are modest and cannot explain the severity of cognitive impairments identified in many children with epilepsy, suggesting that seizures and discharges are likely contributors to cognitive impairment but there must be additional factors driving abnormal outcomes.

\section{The Impact of Etiology}

In the latest proposal for the classification of epilepsies, it is suggested that etiology should be considered in three groups: genetic, structural/metabolic, and unknown cause. The unknown cause does not mean that there is not a disease leading to seizures, but simply that one has not been identified.

\section{Genetic Etiology}

Advances in technologies now allow extensive examination of the genome of epileptic patients and their families (Epi4K Consortium et al.2013). Regularly, new mutations, deletions, single nucleotide polymorphisms (SNPs), and copy number variants are being identified as potential causes of epilepsy. In some cases, mutations of a single gene can explain seizure phenotypes in a significant proportion of patients affected by a given syndrome or family of syndromes. A remarkable example of this phenomenon is the Dravet syndrome (DS) in which $>80 \%$ of patients suffer from a mutation of SCN1a (Harkin et al. 2007), a gene coding for a voltage-gated sodium channel $\left(\mathrm{Na}_{\mathrm{v}} 1.1\right)$. DS is associated with severe seizures and often profound cognitive impairment. Mutations of $\mathrm{Na}_{\mathrm{v}} 1.1$ have also been identified in generalized epilepsy with febrile seizures+ (GEFS+) (Escayg et al. 2000), and it appears that the severity of the epilepsy phenotype depends on whether the alteration of the gene results in a loss of function of the channel or not (Catterall et al. 2010). Interestingly, there is no direct relationship between the severity and frequency of seizures and the severity of cognitive outcome. Therefore, seizures cannot be the only factor responsible for cognitive impairment. A study in which $\mathrm{Na}_{\mathrm{v}} 1.1$ was down-regulated in the medial septum showed that this led to a disruption in the septohippocampal network with impairments in hippocampal-dependent functions, but in the absence of any seizures. This strongly supports the view that there are direct negative cognitive effects of the mutation and that seizures are not required for cognitive impairment (Bender et al. 2013).

\section{Structural Etiology}

The two structural etiologies that will be considered in this section are hippocampal sclerosis and malformations of cortical development (MCD).

Temporal lobe epilepsy associated with mesial temporal sclerosis is a common form of epilepsy identified in patients undergoing epilepsy surgery (Babb and Brown 1986). The lithium pilocarpine model recapitulates many of the features of this human condition (Cavalheiro 1995), including marked memory deficits in the Morris water maze (Muller et al. 2009a,b). Although epileptic activity may contribute to adverse cognitive processing in hippocampal sclerosis, it is undeniable that the brain injury is also contributing to these outcomes. From a behavioral perspective, there are a lot of data showing impairments in spatial cognition as 
would be expected in animals that have hippocampal injury. At the systems level, there are data that reveal alterations in plasticity, singleunit firing activity, oscillatory activity, and functional connectivity. For instance, kainic acid-induced status epilepticus in newborn, infant (Lynch et al. 2000a,b), or adult (Inostroza et al. 2013) rats result in alteration of both LTP and STP with consequent working memory and reference memory deficits.

Place cells have been shown to be less precise and less stable over time in animals with hippocampal sclerosis, and the severity of the placecell disruption is related to performance in the water maze (Liu et al. 2003). Phase precession in the same model (Lenck-Santini and Holmes 2008) is absent in a portion but not all of the CA1 pyramidal cells recorded. At the population level, the overall organization of firing sequences, normally representing the trajectories of the animal, becomes incoherent with regard to the spatial organization of the environment. Although these data have concentrated on identifying place-cell abnormalities, it is recognized that nonplace pyramidal cells also fire during behavior, and it is likely that these cells are also involved in information processing. It is also recognized that that multiple pyramidal cells are firing in a coordinated fashion. Functional networks evaluating how hippocampal pyramidal cells interact reveals that, in hippocampal sclerosis, each pyramidal cell is functionally related to a greater number of other pyramidal cells and that the extent of this hyperconnectivity is correlated with how well the rat can perform a hippocampal-dependent alternation task (Tyler et al. 2012). In addition, the quality of the reactivation of networks formed during rest is also predictive of performance. Therefore, there is clear evidence that surviving hippocampal pyramidal cells are formed into abnormal hippocampal circuitry, which results in cognitive impairments. Interestingly, however, these networks seem to function well in terms of replay in sleep, suggesting that the system responsible for this activity is extremely robust to injury.

Hippocampal $\theta$ oscillations have also been shown to be abnormal in mesial temporal scle- rosis. In animal models of temporal lobe epilepsy, both frequency and amplitude of $\theta$ rhythm is reduced (Iriarte et al. 2006; Chauviere et al. 2009). This may be related to a selective loss of medial septum GABAergic projecting neurons (Garrido Sanabria et al. 2006) as well as hippocampal PV interneurons immediately after the initiating status epilepticus (Bouilleret et al. 2000). In addition, OLM cells show altered intrinsic and synaptic properties resulting in a dysregulation of natural $\theta$ rhythmicity ( $\mathrm{Du}-$ gladze et al. 2007). Such dysregulation has been investigated by studying the relationships between running speed and the amplitude and frequency of $\theta$ recorded from the hippocampus. The quality of that relationship is disrupted in animals with hippocampal sclerosis, and the severity of the disruption is predictive of performance (Richard et al. 2013). All of these data suggest that it is not simply neuronal death and a reduction in the neural machinery required for processing, but rather a change in the neural networks of the surviving neurons.

Another common set of etiologies in children with epilepsy are MCDs. As with all etiologies, it is essential to establish whether the etiology has a significant impact on cognition. Methylazoxymethanol administered to pregnant dams at E17 results in a bilateral malformation of hippocampal pyramidal cells seen as dispersion of CA1 and CA3 layers (ChevassusAu-Louis et al. 1999; Lucas et al. 2011). The animals with MCD display abnormalities in cognitive tasks including the Morris water maze and in a place-avoidance task (Lucas et al. 2011; Jenks et al. 2013; Snyder et al. 2013). Both of these tasks are hippocampal dependent. In a subset of animals, flurothyl-induced seizures administered in early life had no additional impact on outcome. These data support the view that etiology is a major determinant of cognitive outcomes and deserves consideration in treatment algorithms. Unfortunately, many etiologies are considered to be fixed (e.g., hippocampal neuronal loss in temporal lobe epilepsy and MCD) and, therefore, untreatable. However, in animal models of MCDs, it is clear that modification of environments and overtraining paradigms result in dramatic improve- 
Cognitive Impairment in Epilepsy

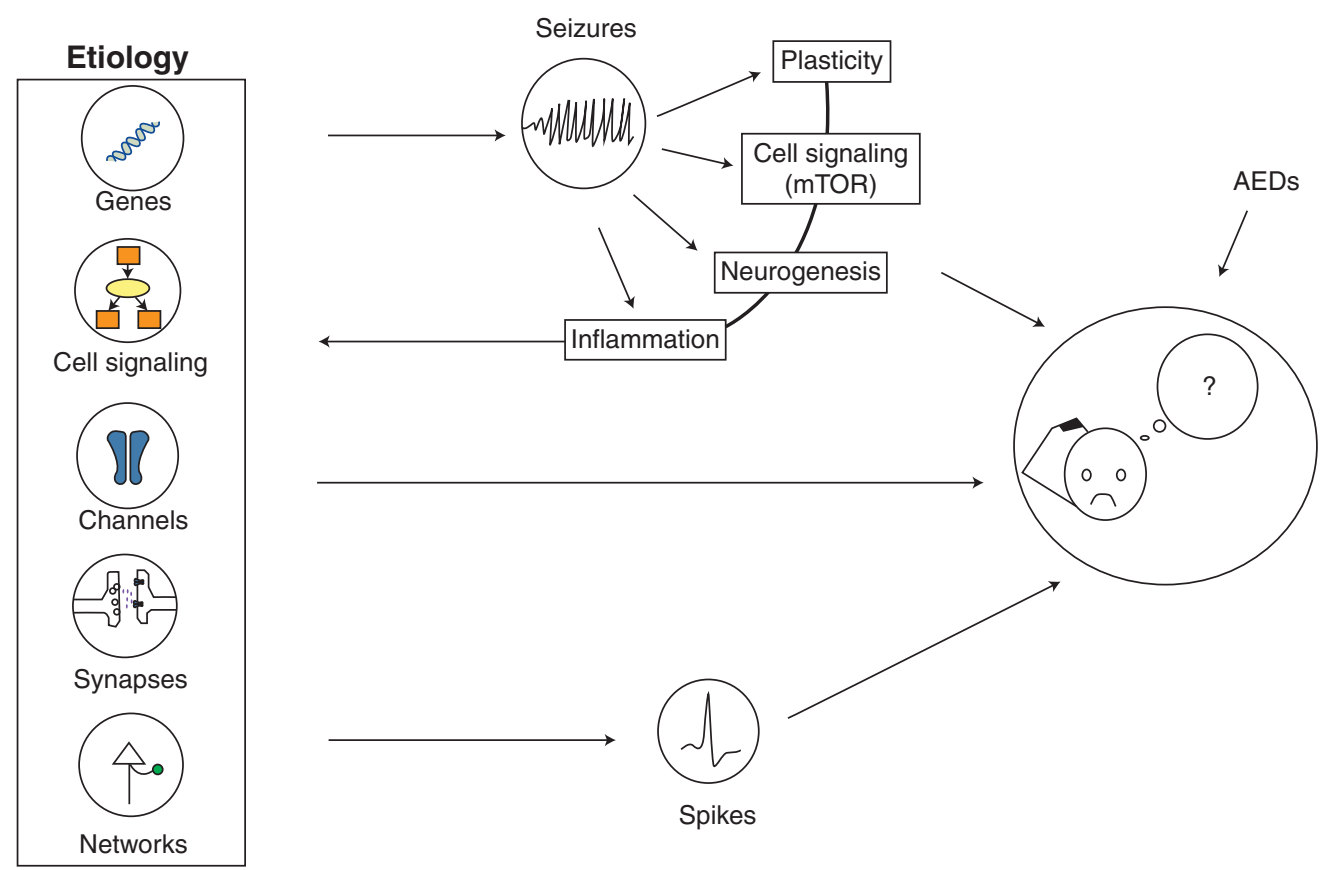

Figure 2. Summary illustration describing the ensemble of processes leading to cognitive impairment in epilepsy. mTOR, mammalian target of rapamycin; AEDs, antiepileptic drugs.

ments in cognitive abilities (Jenks et al. 2013). Thus, even though the structural malformation is unchanged, there has been some alteration in functional networks allowing improved performance. The systems-level mechanisms underlying these behavioral improvements have not yet been clarified.

\section{CONCLUSION}

The cellular substrates of cognitive processing are diverse and complex. As we saw, there is increasing evidence that neuronal synchrony and neural rhythms play an important role in information processing and neuronal plasticity. We propose (Fig. 2) that the genetic, molecular, and physiological alterations associated with epilepsy, being etiological or a downstream effect from the epileptic condition itself, will have a critical impact on these processes, thereby altering cognitive function. Alterations at the level of specific interneuron/pyramidal cell synapses in a cortical structure could have a dramatic consequence on the way this pyramidal cell processes information. When large populations of neurons are affected, this effect could have multiplicative consequences and propagate an aberrant signal to connected structures. As much as this signal could be epileptiform, it could also carry abnormal information to associated structures, with possible adverse consequences on the main function that the affected systems underlie.

\section{REFERENCES}

Agnihotri NT, Hawkins RD, Kandel ER, Kentros C. 2004. The long-term stability of new hippocampal place fields requires new protein synthesis. Proc Natl Acad Sci 101: 3656-3661.

Aldenkamp AP, Arends J. 2004a. Effects of epileptiform EEG discharges on cognitive function: Is the concept of "transient cognitive impairment" still valid? Epilepsy Behav 5: S25-S34.

Aldenkamp A, Arends J. 2004b. The relative influence of epileptic EEG discharges, short nonconvulsive seizures, and type of epilepsy on cognitive function. Epilepsia 45: 54-63.

Aldenkamp AP, Alpherts WC, Dekker MJ, Overweg J. 1990. Neuropsychological aspects of learning disabilities in epilepsy. Epilepsia 31: S9-S20. 
Aldenkamp AP, Arends J, Overweg-Plandsoen TC, van Bronswijk KC, Schyns-Soeterboek A, Linden, Diepman L. 2001. Acute cognitive effects of nonconvulsive difficult-to-detect epileptic seizures and epileptiform electroencephalographic discharges. J Child Neurol 16: 119123.

Aldenkamp AP, Arends J, Verspeek S, Berting M. 2004. The cognitive impact of epileptiform EEG-discharges; relationship with type of cognitive task. Child Neuropsychol 10: $297-305$.

Babb TL, Brown WJ. 1986. Neuronal, dendritic, and vascular profiles of human temporal lobe epilepsy correlated with cellular physiology in vivo. Adv Neurol 44: 949-966.

Barry RJ, Clarke AR. 2013. Resting state brain oscillations and symptom profiles in attention deficit/hyperactivity disorder. Suppl Clin Neurophysiol 62: 275-287.

Barry JM, Rivard B, Fox SE, Fenton AA, Sacktor TC, Muller RU. 2012. Inhibition of protein kinase $\mathrm{M}-\zeta$ disrupts the stable spatial discharge of hippocampal place cells in a familiar environment. J Neurosci 32: 13753-13762.

Bartos M, Vida I, Jonas P. 2007. Synaptic mechanisms of synchronized $\gamma$ oscillations in inhibitory interneuron networks. Nat Rev Neurosci 8: 45-56.

Beck H, Goussakov IV, Lie A, Helmstaedter C, Elger CE. 2000. Synaptic plasticity in the human dentate gyrus. J Neurosci 20: 7080-7086.

Bell B, Lin JJ, Seidenberg M, Hermann B. 2011. The neurobiology of cognitive disorders in temporal lobe epilepsy. Nat Rev Neurol 7: 154-164.

Bender AC, Natola H, Ndong C, Holmes GL, Scott RC, Lenck-Santini PP. 2013. Focal Scnla knockdown induces cognitive impairment without seizures. Neurobiol Dis 54: 297-307.

Berg AT, Scheffer IE. 2011. New concepts in classification of the epilepsies: Entering the 21st century. Epilepsia 52: $1058-1062$.

Berg AT, Hesdorffer DC, Zelko FA. 2011. Special education participation in children with epilepsy: What does it reflect? Epilepsy Behav 22: 336-341.

Binnie CD. 1994. Cognitive impairment-Is it inevitable? Seizure 3: 17-21.

Binnie CD, Kasteleijn-Nolst Trenite DG, Smit AM, Wilkins AJ. 1987. Interactions of epileptiform EEG discharges and cognition. Epilepsy Res 1: 239-245.

Bjornaes H, Stabell K, Henriksen O, Loyning Y. 2001. The effects of refractory epilepsy on intellectual functioning in children and adults. A longitudinal study. Seizure 10: 250-259.

Bliss TV, Lomo T. 1973. Long-lasting potentiation of synaptic transmission in the dentate area of the anaesthetized rabbit following stimulation of the perforant path. J Physiol 232: $331-356$.

Bouilleret V, Loup F, Kiener T, Marescaux C, Fritschy JM. 2000. Early loss of interneurons and delayed subunitspecific changes in $\mathrm{GABA}_{\mathrm{A}}$-receptor expression in a mouse model of mesial temporal lobe epilepsy. Hippocampus 10: 305-324.

Bragin A, Jando G, Nadasdy Z, Hetke J, Wise K, Buzsaki G. 1995. $\gamma(40-100 \mathrm{~Hz})$ oscillation in the hippocampus of the behaving rat. J Neurosci 15: 47-60
Bulteau C, Jambaque I, Viguier D, Kieffer V, Dellatolas G, Dulac O. 2000. Epileptic syndromes, cognitive assessment and school placement: A study of 251 children. Dev Med Child Neurol 42: 319-327.

Buzsaki G, Anastassiou CA, Koch C. 2012. The origin of extracellular fields and currents-EEG, ECoG, LFP and spikes. Nat Rev Neurosci 13: 407-420.

Canavese C, Rigardetto R, Viano V, Vittorini R, Bassi B, Pieri I, Capizzi G. 2007. Are dyslexia and dyscalculia associated with Rolandic epilepsy? A short report on ten Italian patients. Epileptic Disord 9: 432-436.

Canolty RT, Edwards E, Dalal SS, Soltani M, Nagarajan SS, Kirsch HE, Berger MS, Barbaro NM, Knight RT. 2006. High $\gamma$ power is phase-locked to $\theta$ oscillations in human neocortex. Science 313: 1626-1628.

Cantero JL, Atienza M, Stickgold R, Kahana MJ, Madsen JR, Kocsis B. 2003. Sleep-dependent $\theta$ oscillations in the human hippocampus and neocortex. J Neurosci 23: 1089710903.

Caplan R, Siddarth P, Stahl L, Lanphier E, Vona P, Gurbani S, Koh S, Sankar R, Shields WD. 2008. Childhood absence epilepsy: Behavioral, cognitive, and linguistic comorbidities. Epilepsia 49: 1838-1846.

Catterall WA, Kalume F, Oakley JC. 2010. $\mathrm{Na}_{\mathrm{v}} 1.1$ channels and epilepsy. J Physiol 588: 1849-1859.

Cavalheiro EA. 1995. The pilocarpine model of epilepsy. Ital J Neurol Sci 16: 33-37.

Chaix Y, Laguitton V, Lauwers-Cancès V, Daquin G, Cancès C, Démonet JF, Villeneuve N. 2006. Reading abilities and cognitive functions of children with epilepsy: Influence of epileptic syndrome. Brain Dev 28: 122-130.

Chauviere L, Rafrafi N, Thinus-Blanc C, Bartolomei F, Esclapez M, Bernard C. 2009. Early deficits in spatial memory and $\theta$ rhythm in experimental temporal lobe epilepsy. J Neurosci 29: 5402-5410.

Chevassus-Au-Louis N, Jorquera I, Ben-Ari Y, Represa A. 1999. Abnormal connections in the malformed cortex of rats with prenatal treatment with methylazoxymethanol may support hyperexcitability. Dev Neurosci 21:385392.

Cho YH, Giese KP, Tanila H, Silva AJ, Eichenbaum H. 1998. Abnormal hippocampal spatial representations in $\alpha$ CaMKIIT $^{286 \mathrm{~A}}$ and $\mathrm{CREB}^{\alpha \Delta-}$ mice. Science 279: $867-$ 869.

Clarke T, Strug LJ, Murphy PL, Bali B, Carvalho J, Foster S, Tremont G, Gagnon BR, Dorta N, Pal DK. 2007. High risk of reading disability and speech sound disorder in rolandic epilepsy families: Case-control study. Epilepsia 48: $2258-2265$.

Colgin LL, Denninger T, Fyhn M, Hafting T, Bonnevie T, Jensen O, Moser MB, Moser EL. 2009. Frequency of $\gamma$ oscillations routes flow of information in the hippocampus. Nature 462: 353-357.

Croona C, Kihlgren M, Lundberg S, Eeg-Olofsson O, EegOlofsson KE. 1999. Neuropsychological findings in children with benign childhood epilepsy with centrotemporal spikes. Dev Med Child Neurol 41: 813-818.

Deltour L, Barathon M, Quaglino V, Vernier MP, Despretz P, Boucart M, Berquin P. 2007. Children with benign epilepsy with centrotemporal spikes (BECTS) show im- 
paired attentional control: Evidence from an attentional capture paradigm. Epileptic Disord 9: 32-38.

Dragoi G, Harris KD, Buzsaki G. 2003. Place representation within hippocampal networks is modified by long-term potentiation. Neuron 39: 843-853.

Dubé CM, Zhou JL, Hamamura M, Zhao Q, Ring A, Abrahams J, McIntyre K, Nalcioglu O, Shatskih T, Baram TZ, et al. 2009. Cognitive dysfunction after experimental febrile seizures. Exp Neurol 215: 167-177.

Dugladze T, Vida I, Tort AB, Gross A, Otahal J, Heinemann U, Koppell NJ, Gloveli T. 2007. Impaired hippocampal rhythmogenesis in a mouse model of mesial temporal lobe epilepsy. Proc Natl Acad Sci 104: 17530-17535.

Epi4K Consortium, Epilepsy Phenome/Genome Project; Allen AS, Berkovic SF, Cossette P, Delanty N, Dlugos D, Eichler EE, Epstein MP, Glauser T, et al. 2013. De novo mutations in epileptic encephalopathies. Nature 501: 217-221.

Escayg A, MacDonald BT, Meisler MH, Baulac S, Huberfeld G, An-Gourfinkel I, Brice A, LeGuern E, Moulard B, Chaigne D, et al. 2000. Mutations of SCN1A, encoding a neuronal sodium channel, in two families with GEFS +2 . Nat Genet 24: 343-345.

Farwell JR, Dodrill CB, Batzel LW. 1985. Neuropsychological abilities of children with epilepsy. Epilepsia 26: 395-400.

Fastenau PS, Jianzhao S, Dunn DW, Austin JK. 2008. Academic underachievement among children with epilepsy: Proportion exceeding psychometric criteria for learning disability and associated risk factors. J Learn Disabil 41: 195-207.

Felker MV, Walker LM, Sokol DK, Edwards-Brown M, Chang BS. 2011. Early cognitive and behavioral problems in children with nodular heterotopia. Epilepsy Behav 22: 523-526.

Fisher RS, Acevedo C, Arzimanoglou A, Bogacz A, Cross JH, Elger CE, Engel J Jr, Forsgren L, French JA, Glynn M, et al. 2014. ILAE official report: A practical clinical definition of epilepsy. Epilepsia 55: 475-482.

Fried I, MacDonald KA, Wilson CL. 1997. Single neuron activity in human hippocampus and amygdala during recognition of faces and objects. Neuron 18: 753-765.

Fries P. 2005. A mechanism for cognitive dynamics: Neuronal communication through neuronal coherence. Trends Cogn Sci 9: 474-80.

Fries P. 2009. The model- and the data- $\gamma$. Neuron 64: 601602.

Garrido Sanabria ER, Castaneda MT, Banuelos C, PerezCordova MG, Hernandez S, Colom LV. 2006. Septal GABAergic neurons are selectively vulnerable to pilocarpine-induced status epilepticus and chronic spontaneous seizures. Neuroscience 142: 871-883.

Geisler C, Diba K, Pastalkova E, Mizuseki K, Royer S, Buzsaki G. 2010. Temporal delays among place cells determine the frequency of population $\theta$ oscillations in the hippocampus. Proc Natl Acad Sci 107: 7957-7962.

Georgopoulos AP, Kalaska JF, Caminiti R, Massey JT. 1982. On the relations between the direction of two-dimensional arm movements and cell discharge in primate motor cortex. J Neurosci 2: 1527-1537.
Gibbs FA, Lennox WG, Gibbs EL. 1936. The electroencephalogram in diagnosis and in localization of epileptic seizures. Arch Neurol Psychiatry 36: 1225-1235.

Givens B, Olton DS. 1994. Local modulation of basal forebrain: Effects on working and reference memory. J Neurosci 14: $3578-3587$.

Gray CM, Konig P, Engel AK, Singer W. 1989. Oscillatory responses in cat visual cortex exhibit inter-columnar synchronization which reflects global stimulus properties. Nature 338: 334-337.

Guerrini R, Pellacani S. 2012. Benign childhood focal epilepsies. Epilepsia 53: 9-18.

Gupta AS, van der Meer MA, Touretzky DS, Redish AD. 2012. Segmentation of spatial experience by hippocampal $\theta$ sequences. Nat Neurosci 15: 1032-1039.

Hangya B, Borhegyi Z, Szilagyi N, Freund TF, Varga V. 2009. GABAergic neurons of the medial septum lead the hippocampal network during $\theta$ activity. J Neurosci 29: 80948102.

Harkin LA, McMahon JM, Iona X, Dibbens L, Pelekanos JT, Zuberi SM, Sadleir LG, Andermann E, Gill D, Farrell K, et al. 2007. The spectrum of SCN1A-related infantile epileptic encephalopathies. Brain 130: 843-852.

Harris KD, Csicsvari J, Hirase H, Dragoi G, Buzsaki G. 2003. Organization of cell assemblies in the hippocampus. $\mathrm{Na}$ ture 424: 552-556.

Hermann BP, Seidenberg M, Bell B. 2002. The neurodevelopmental impact of childhood onset temporal lobe epilepsy on brain structure and function and the risk of progressive cognitive effects. Prog Brain Res 135: 429438.

Hernan AE, Holmes GL, Isaev D, Scott RC, Isaeva E. 2013. Altered short-term plasticity in the prefrontal cortex after early life seizures. Neurobiol Dis 50: 120-126.

Hernan AE, Alexander A, Jenks KR, Barry J, Lenck-Santini PP, Isaeva E, Holmes GL, Scott RC. 2014a. Focal epileptiform activity in the prefrontal cortex is associated with long-term attention and sociability deficits. Neurobiol Dis 63: 25-34.

Hernan AE, Alexander A, Lenck-Santini PP, Scott RC, Holmes GL. 2014b. Attention deficit associated with early life interictal spikes in a rat model is improved with ACTH. PLOS ONE 9: e89812.

Holmes GL, Lenck-Santini PP. 2006. Role of interictal epileptiform abnormalities in cognitive impairment. Epilepsy Behav 8: 504-515.

Hubel DH, Wiesel TN. 1959. Receptive fields of single neurones in the cat's striate cortex. J Physiol 148: 574-591.

Inostroza M, Binder S, Born J. 2013. Sleep-dependency of episodic-like memory consolidation in rats. Behav Brain Res 237: 15-22.

Iriarte J, Urrestarazu E, Artieda J, Valencia M, Levan P, Viteri C, Alegre M. 2006. Independent component analysis in the study of focal seizures. J Clin Neurophysiol 23: 551558.

Isaeva E, Isaev D, Savrasova A, Khazipov R, Holmes GL. 2010. Recurrent neonatal seizures result in long-term increases in neuronal network excitability in the rat neocortex. Eur J Neurosci 31: 1446-1455.

Jenks KR, Lucas MM, Duffy BA, Robbins AA, Gimi B, Barry JM, Scott RC. 2013. Enrichment and training improve 
cognition in rats with cortical malformations. PLoS ONE 8: e84492.

Jensen FE. 1999. Acute and chronic effects of seizures in the developing brain: Experimental models. Epilepsia 40: S51-S58.

Jones MW, Wilson MA. 2005. $\theta$ Rhythms coordinate hippocampal-prefrontal interactions in a spatial memory task. PLoS Biol 3: e402.

Karnam HB, Zhou JL, Huang LT, Zhao Q, Shatskikh T, Holmes GL. 2009. Early life seizures cause long-standing impairment of the hippocampal map. Exp Neurol 217: $378-387$.

Kasteleijn-Nolst Trenite DG, Bakker DJ, Binnie CD, Buerman A, Van RM. 1988. Psychological effects of subclinical epileptiform EEG discharges. I: Scholastic skills. Epilepsy Res 2: $111-116$.

Kasteleijn-Nolst Trenite DG, Vermeiren R. 2005. The impact of subclinical epileptiform discharges on complex tasks and cognition: Relevance for aircrew and air traffic controllers. Epilepsy Behav 6: 31-34.

Kentros C, Hargreaves E, Hawkins RD, Kandel ER, Shapiro M, Muller RV. 1998. Abolition of long-term stability of new hippocampal place cell maps by NMDA receptor blockade. Science 280: 2121-2126.

Kilavik BE, Confais J, Riehle A. 2014. Signs of timing in motor cortex during movement preparation and cue anticipation. Adv Exp Med Biol 829: 121-142.

Klausberger T, Somogyi P. 2008. Neuronal diversity and temporal dynamics: The unity of hippocampal circuit operations. Science 321: 53-57.

Kleen JK, Scott RC, Holmes GL, Lenck-Santini PP. 2010. Hippocampal interictal spikes disrupt cognition in rats. Ann Neurol 67: 250-257.

Kleen JK, Scott RC, Holmes GL, Roberts DW, Rundle MM, Testorf M, Lenck-Santini PP, Jobst BC. 2013. Hippocampal interictal epileptiform activity disrupts cognition in humans. Neurology 81: 18-24.

Lachaux JP, Rodriguez E, Martinerie J, Varela FJ. 1999. Measuring phase synchrony in brain signals. Hum Brain Mapp 8: 194-208.

Lenck-Santini PP, Holmes GL. 2008. Altered phase precession and compression of temporal sequences by place cells in epileptic rats. J Neurosci 28: 5053-5062.

Levi R, Camhi JM. 2000. Population vector coding by the giant interneurons of the cockroach. J Neurosci 20: 38223829.

Lin H, Hangya B, Fox SE, Muller RU. 2012. Repetitive convulsant-induced seizures reduce the number but not precision of hippocampal place cells. J Neurosci 32: 41634178.

Lisman J. 2005. The $\theta / \gamma$ discrete phase code occurring during the hippocampal phase precession may be a more general brain coding scheme. Hippocampus 15: 913-922.

Liu X, Muller RU, Huang LT, Kubie JL, Rotenberg A, Rivard B, Cilio MR, Holmes GL. 2003. Seizure-induced changes in place cell physiology: Relationship to spatial memory. J Neurosci 23: 11505-11515.

Llinas R, Ribary U. 1993. Coherent 40-Hz oscillation characterizes dream state in humans. Proc Natl Acad Sci 90: 2078-2081.
Loring DW, Meador KJ, Lee GP. 2004. Determinants of quality of life in epilepsy. Epilepsy Behav 5: 976-980.

Loughman A, Bowden SC, D’Souza W. 2014. Cognitive functioning in idiopathic generalised epilepsies: A systematic review and meta-analysis. Neurosci Biobehav Rev 43: $20-34$.

Lucas MM, Lenck-Santini PP, Holmes GL, Scott RC. 2011. Impaired cognition in rats with cortical dysplasia: Additional impact of early-life seizures. Brain 134: 16841693.

Lynch M, Sayin U, Golarai G, Sutula T. 2000a. NMDA receptor-dependent plasticity of granule cell spiking in the dentate gyrus of normal and epileptic rats. J Neurophysiol 84: $2868-2879$.

Lynch M, Sayin U, Bownds J, Janumpalli S, Sutula T. 2000b. Long-term consequences of early postnatal seizures on hippocampal learning and plasticity. Eur J Neurosci 12: 2252-2264.

McHugh TJ, Blum KI, Tsien JZ, Tonegawa S, Wilson MA. 1996. Impaired hippocampal representation of space in CA1-specific NMDAR1 knockout mice. Cell 87: 13391349.

Miltner WH, Braun C, Arnold M, Witte H, Taub E. 1999. Coherence of $\gamma$-band EEG activity as a basis for associative learning. Nature 397: 434-436.

Montgomery SM, Buzsaki G. 2007. $\gamma$ Oscillations dynamically couple hippocampal CA3 and CA1 regions during memory task performance. Proc Natl Acad Sci 104: 14495-14500.

Morris RG, Anderson E, Lynch GS, Baudry M. 1986. Selective impairment of learning and blockade of long-term potentiation by an $N$-methyl-D-aspartate receptor antagonist, AP5. Nature 319: 774-746.

Moser EI, Kropff E, Moser MB. 2008. Place cells, grid cells, and the brain's spatial representation system. Annu Rev Neurosci 31: 69-89.

Muller R. 1996. A quarter of a century of place cells. Neuron 17: 813-822.

Muller CJ, Groticke I, Bankstahl M, Loscher W. 2009a. Behavioral and cognitive alterations, spontaneous seizures, and neuropathology developing after a pilocarpine-induced status epilepticus in C57BL/6 mice. Exp Neurol 219: 284-297.

Muller CJ, Bankstahl M, Groticke I, Loscher W. 2009b. Pilocarpine vs. lithium-pilocarpine for induction of status epilepticus in mice: Development of spontaneous seizures, behavioral alterations and neuronal damage. Eur J Pharmacol 619: 15-24.

Northcott E, Connolly AM, Berroya A, Sabaz M, McIntyre J, Christie J, Taylor A, Batchelor J, Bleasel AF, Lawson JA, et al. 2005. The neuropsychological and language profile of children with benign rolandic epilepsy. Epilepsia 46: 924930.

O'Keefe J, Nadel L. 1978. The hippocampus as a cognitive map. Clarendon, Oxford.

Oostrom KJ, Schouten A, Kruitwagen CL, Peters AC, Jennekens-Schinkel A. 2003. Behavioral problems in children with newly diagnosed idiopathic or cryptogenic epilepsy attending normal schools are in majority not persistent. Epilepsia 44: 97-106. 
Pastalkova E, Serrano P, Pinkhasova D, Wallace E, Fenton AA, Sacktor TC. 2006. Storage of spatial information by the maintenance mechanism of LTP. Science 313: 1141 1444.

Pinton F, Ducot B, Motte J, Arbuès AS, Barondiot C, Barthez MA, Chaix Y, Cheminal R, Livet MO, Penniello MJ, et al. 2006. Cognitive functions in children with benign childhood epilepsy with centrotemporal spikes (BECTS). Epileptic Disord 8: 11-23.

Quian QR, Kraskov A, Mormann F, Fried I, Koch C. 2014 Single-cell responses to face adaptation in the human medial temporal lobe. Neuron 22: 363-369.

Raspall-Chaure M, Neville BG, Scott RC. 2008. The medical management of the epilepsies in children: Conceptual and practical considerations. Lancet Neurol 7: 57-69.

Reid IC, Stewart CA. 1997. Seizures, memory and synaptic plasticity. Seizure 6: 351-359.

Richard GR, Titiz A, Tyler A, Holmes GL, Scott RC, LenckSantini PP. 2013. Speed modulation of hippocampal $\theta$ frequency correlates with spatial memory performance. Hippocampus 23: 1269-1279.

Ronen GM, Streiner DL, Rosenbaum P. 2003. Health-related quality of life in childhood epilepsy: Moving beyond "seizure control with minimal adverse effects." Health Qual Life Outcomes 1: 36.

Salinas E, Abbott LF. 1994. Vector reconstruction from firing rates. J Comput Neurosci 1: 89-107.

Sanchez-Carpintero R, Neville BG. 2003. Attentional ability in children with epilepsy. Epilepsia 44: 1340-1349.

Schubert M, Siegmund H, Pape HC, Albrecht D. 2005. Kindling-induced changes in plasticity of the rat amygdala and hippocampus. Learn Mem 12: 520-526.

Schwab RS. 1939. A method of measuring consciousness in attacks of petit mal epilepsy. Arch Neurol Psychiatry 41: 215-217.

Seidenberg M, Beck N, Geisser M, Giordani B, Sackellares JC, Berent S, Dreifuss FE, Boll TJ. 1986. Academic achievement of children with epilepsy. Epilepsia 27: 753-759.

Snyder MA, Adelman AE, Gao WJ. 2013. Gestational methylazoxymethanol exposure leads to NMDAR dysfunction in hippocampus during early development and lasting deficits in learning. Neuropsychopharmacology 38: 328 340 .
Spencer KM, Nestor PG, Niznikiewicz MA, Salisbury DF, Shenton ME, McCarley RW. 2003. Abnormal neural synchrony in schizophrenia. J Neurosci 23: 7407-7411.

Tyler AL, Mahoney JM, Richard GR, Holmes GL, LenckSantini PP, Scott RC. 2012. Functional network changes in hippocampal CA1 after status epilepticus predict spatial memory deficits in rats. J Neurosci 32: 11365-11376.

Uhlhaas PJ, Singer W. 2010. Abnormal neural oscillations and synchrony in schizophrenia. Nat Rev Neurosci 11: $100-113$.

Van BP. 2013. Epileptic encephalopathy with continuous spike-waves during slow-wave sleep including LandauKleffner syndrome. Handb Clin Neurol 111: 635-640.

Verrotti A, D’Egidio C, Agostinelli S, Parisi P, Chiarelli F, Coppola G. 2011. Cognitive and linguistic abnormalities in benign childhood epilepsy with centrotemporal spikes. Acta Paediatr 100: 768-772.

Vinayan KP, Biji V, Thomas SV. 2005. Educational problems with underlying neuropsychological impairment are common in children with benign epilepsy of childhood with centrotemporal spikes (BECTS). Seizure 14: 207212.

Viskontas IV, Quiroga RQ, Fried I. 2009. Human medial temporal lobe neurons respond preferentially to personally relevant images. Proc Natl Acad Sci 106: 21329 21334.

Wagner H, Brill S, Kempter R, Carr CE. 2005. Microsecond precision of phase delay in the auditory system of the barn owl. J Neurophysiol 94: 1655-1658.

Winson J. 1978. Loss of hippocampal $\theta$ rhythm results in spatial memory deficit in the rat. Science 201: 160-163.

Wilson MA, McNaughton BL. 1993. Dynamics of the hippocampal ensemble code for space. Science 261: 10551058.

Zhou JL, Shatskikh TN, Liu X, Holmes GL. 2007. Impaired single cell firing and long-term potentiation parallels memory impairment following recurrent seizures. Eur J Neurosci 25: 3667-3677.

Zhou C, Lippman JJ, Sun H, Jensen FE. 2011. Hypoxiainduced neonatal seizures diminish silent synapses and long-term potentiation in hippocampal CAl neurons. J Neurosci 31: 18211-18222. 


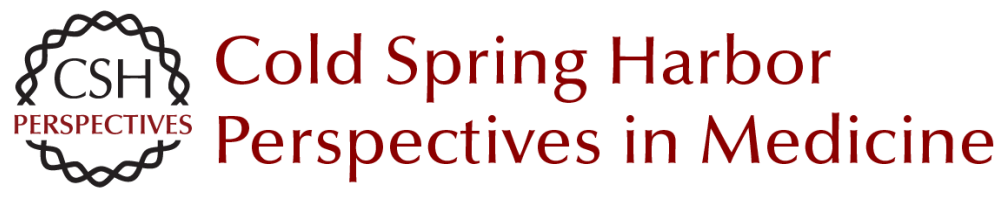

\section{Mechanisms Responsible for Cognitive Impairment in Epilepsy}

Pierre-Pascal Lenck-Santini and Rodney C. Scott

Cold Spring Harb Perspect Med 2015; doi: 10.1101/cshperspect.a022772 originally published online September 3, 2015

\section{Subject Collection Epilepsy: The Biology of a Spectrum Disorder}

The Epilepsy Spectrum: Targeting Future Research Challenges

Gregory L. Holmes and Jeffrey L. Noebels

Role of Sodium Channels in Epilepsy

David I. Kaplan, Lori L. Isom and Steven Petrou

\section{Mechanisms of Action of Antiseizure Drugs and the Ketogenic Diet \\ Michael A. Rogawski, Wolfgang Löscher and Jong M. Rho}

Epilepsy and Autism

Ashura W. Buckley and Gregory L. Holmes

Immunity and Inflammation in Epilepsy Annamaria Vezzani, Bethan Lang and Eleonora Aronica

Hyperpolarization-Activated Cyclic

Nucleotide-Gated (HCN) Channels in Epilepsy Gary P. Brennan, Tallie Z. Baram and Nicholas P. Poolos

The Role of Calcium Channels in Epilepsy Sanjeev Rajakulendran and Michael G. Hanna

Interneuron Transplantation as a Treatment for Epilepsy

Robert F. Hunt and Scott C. Baraban
Common Mechanisms Underlying

Epileptogenesis and the Comorbidities of

Epilepsy

Andrey Mazarati and Raman Sankar

The Diathesis-Epilepsy Model: How Past Events Impact the Development of Epilepsy and

Comorbidities

Christophe Bernard

Potassium Channels in Epilepsy

Rüdiger Köhling and Jakob Wolfart

GABAergic Synchronization in Epilepsy Roustem Khazipov

Status Epilepticus

Syndi Seinfeld, Howard P. Goodkin and Shlomo Shinnar

Neonatal and Infantile Epilepsy: Acquired and

Genetic Models Aristea S. Galanopoulou and Solomon L. Moshé

Epigenetics and Epilepsy

David C. Henshall and Katja Kobow

Microcircuits in Epilepsy: Heterogeneity and Hub Cells in Network Synchronization

Anh Bui, Hannah K. Kim, Mattia Maroso, et al.

For additional articles in this collection, see http://perspectivesinmedicine.cshlp.org/cgi/collection/ 